\title{
Lateral Humeral Epicondyle
}

National Cancer Institute

\section{Source}

National Cancer Institute. Lateral Humeral Epicondyle. NCI Thesaurus. Code C139202.

A bone prominence at the distal end of the humerus to which the radial collateral

ligament of the elbow joint, the anconeus and supinator muscles, and the common

extensor tendon are attached. 